AN APPROACH TO THE STUDY OF MONEY AND NONMONEY EXCHANGE STRUCTURES

by

Neil Wallace

Discussion Paper No. 6, June 1971

\footnotetext{
Center for Economic Research

Department of Economics

University of Minnesota

Minneapolis, Minnesota 55455
} 


\section{AN APPROACH TO THE STUDY OF MONEY AND NONMONEY EXCHANGE STRUCTURES*}

Neil Wallace

\section{Introduction}

There have recently been a number of attempts to provide a model within which a money economy or, as I prefer to call it, a money exchange structure emerges as a special case as an implication of optimizing behavior. In this paper, I shal1 make only a very modest attempt in that direction. I shall focus entirely on the supply of exchange services, taking the demand for such services as given, and shall furthermore assume that transaction services are provided in the form of dealer markets, markets in which there is a dealer who stands ready to buy and sell on demand. Moreover, each such market shall be assumed to be a market in only two commodities, the dealer in which, in order to be able to buy and sell on demand, holds inventories of both commodities and, hence, bears inventory holding costs and, perhaps, other costs. Then, given a list of $n$ commodities for which exchange services are to be provided, I ask the question: for what commodity pairs will there be markets?

In some ways the assumptions and the question posed are analogous to the following transportation problem. Given a set of $n$ distinct locations, what shall be the road network that connects them? To assume that demand conditions for transaction services are given is analogous to assuming

* An earlier version of this paper was presented at the December 1970 meetings of the Econometric Society. In revising the paper, I benefited greatly from suggestions made by Professor J. Ostroy of U.C.L.A., who discussed the paper at those meetings. I alone am responsible for the defects that remain. 
that there is a desired network of trips among the $n$ locations. To assume that the demand for transaction services is independent of the cost of transacting--which is what we assume throughout this paper--is analogous to assuming that the desired destination network is independent of the cost of trips. To assume that there is a list of commodities for which exchange services are to be provided is analogous to assuming that a road network be chosen that makes it possible to travel from any location to any other, but not necessarily directly.

But what then does this have to do with a money economy or a money exchange structure? Given $n$ commodities, I define a money exchange structure as one that consists of only n-l markets, where those markets are such that there exists a single commodity that is dealt with in every market. If there exists such a commodity, I shall call it the money commodity.- While that definition may appear too strict to some people, it no doubt captures what we mean by a money exchange structure. The implied definition of money--namely, that it be an intermediary commodity for all exchanges--is consistent with the assumed role of money in models of the demand for money as a medium of exchange; the inventory models of Baumol, Tobin, and Miller and Orr. To see how special is the money exchange structure, we may turn again to the transportation analogy; the road network that corresponds to the money exchange structure as : he have defined it is one in which all roads emanate from a single location that might be called the hub. To travel between any other two locations, one takes two roads, in effect, and passes through the hub.

We shall begin the discussion for the case of three commodities. That is the smallest number for which interesting questions about the exchange

/ Robert Clower has suggested as a definition of a money economy, one in which money is one of the goods traded in every market. See "A Reconsideration of the Microfoundations of Monetary Theory," Western Economic Journal, Vol. 6, No. 1, December 1967, p. 1 . 
structure arise. If there are only two commodities, there are no grounds for calling the exchange structure a money or nonmoney structure, and no grounds for calling one of the commodities the money commodity or the medium of exchange. With three commodities, those questions arise.

Subject to the condition that a11 commodities be exchangeable, with three commodities, there are four possible market structures.

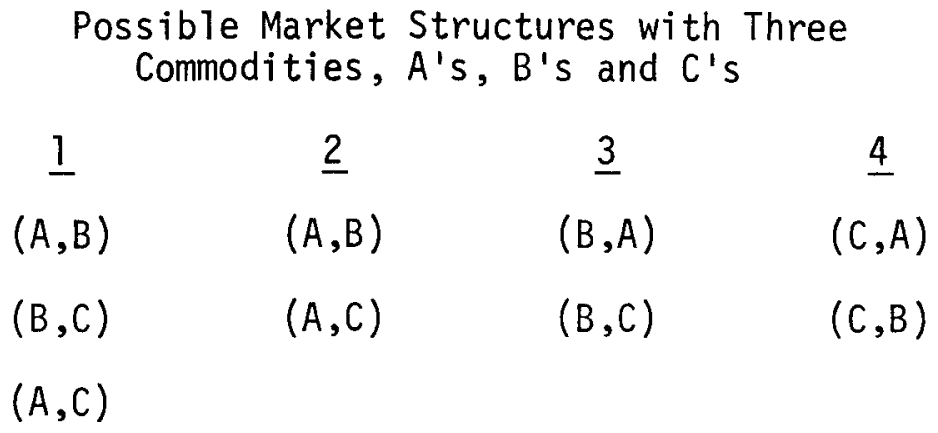

Here a market is denoted by an unordered pair so that $(A, B)$ has the same meaning as $(B, A)$, a dealer market in which $A$ 's can be traded directly for $B$ 's and vice versa. Each of the structures except 1 qualifies as a money exchange structure. In 3 , for example, $B$ is the money commodity. To test whether that notion accords with your intuition, suppose the three commodities are national currencies--e.g., A's are U.S. dollars, B's are U.K. pounds, and C's are French francs. Then structure 3 consists of two markets, a dollar-pound market and a franc-pound market, so that to exchange francs for dollars, one must make transactions in two markets using pounds as an intermediary. I would then say that pounds are playing the role of an international money. 


\section{The Demand for Transaction or Dealer Services}

Demand conditions shall be expressed as average desired trades per unit time, analogous to average desired trips per unit time from one location to another. Specifically, I define $T(I, J)$ as average desired exchanges of I for $J$ measured in units of I per unit time. The T's are described as average rates per unit time because the actual process generating transactions is assumed to be random and discrete which is what necessitates the holding of inventories by dealers. From the T's we can derive desired transaction rates in particular markets, which are denoted by t's; $t(A, B)$ is the desired transaction rate in the $(A, B)$ market measured in units of $A$ handled by the dealer per unit time. Before doing that, though, I shall define transaction fees and exchange ratios net of transaction fees. I define $P(I, J)$ as the exchange ratio between $I$ and $J$ net of transaction costs measured in units of I per unit $J$, and $f(i j)$ as the fee per I handled in the $(\mathrm{I}, \mathrm{J})$ market.

Even if the T's are independent of the costs of transacting, which is what we assume, the t's are not. In the three-commodity world, the demand for transaction services in the $(A, B)$ market, $t(A, B)$, depends on the cost of dealing in that market relative to the costs of dealing in the other two markets, the $(B, C)$ and $(C, A)$ markets. One way to approach this is to note that if $t(A, B)$ is to be non-zero, then the $(A, B)$ market must be best for desired trades between $A$ and $B$. If it is not best for those trades, then $(A, B)$ cannot be part of a least cost exchange route for trades between $A$ and $C$ and between $B$ and $C$. Thus, we first ask under what conditions 
will it be cheapest to carry out trades between $A$ and $B$ in the $(A, B)$ market. Suppose a transactor wishes to exchange one unit of $A$ for $B$. Two exchange routes are feasible, and each gets him $1 / P(A, B)$ units of $B$, but he may bear different transaction fees in the two cases. If he deals in the $(A, B)$ market the fee is $f(a b)$. If he deals by way of the $(A, C)$ and $(B, C)$ markets, he bears a total fee equal to $f(a c)+f(b c) / P(A, B)$. Thus, he will deal in the $(A, B)$ market if

$$
f(a b) \leq f(a c)+f(b c) / P(A, B)
$$

The same comparison arises for exchanges of B for A. Thus, condition (1) is necessary and sufficient for there to be a non-zero demand for services in the $(A, B)$ market. Similar conditions can be derived for the $(A, C)$ and $(B, C)$ markets. They are, respectively,

$$
f(a c) \leq f(a b)+f(b c) / P(A, B)
$$

and

$$
f(b c) \leq[f(a b)+f(a c)] P(A, B) .
$$

We may now deduce the demand for exchange services in any of the markets. Thus, for example, for the $(A, B)$ market,

$$
t(A, B)=\left\{\begin{array}{l}
0, \text { if (1) does not hold. } \\
T(A, B)+T(B, A) P(A, B), \text { if }(1)-(3) \text { hold. } \\
T(A, B)+T(B, A) P(A, B)+[T(B, C)+T(C, B) P(B, C)] / P(A, B), \\
\text { if only }(1) \text { and (2) hold. } \\
T(A, B)+T(B, A) P(A, B)+T(A, C)+T(C, A) P(A, C) \text {, if } \\
\text { only (1) and (3) hold. }
\end{array}\right.
$$

Drawn as a function of the fee in the $(A, B)$ market given the fees in the other markets, the demand for transaction services in the $(A, B)$ market has 
the shape shown in Figure 1.

Figure 1. The Desired Transaction Rate in the $(A, B)$ Market

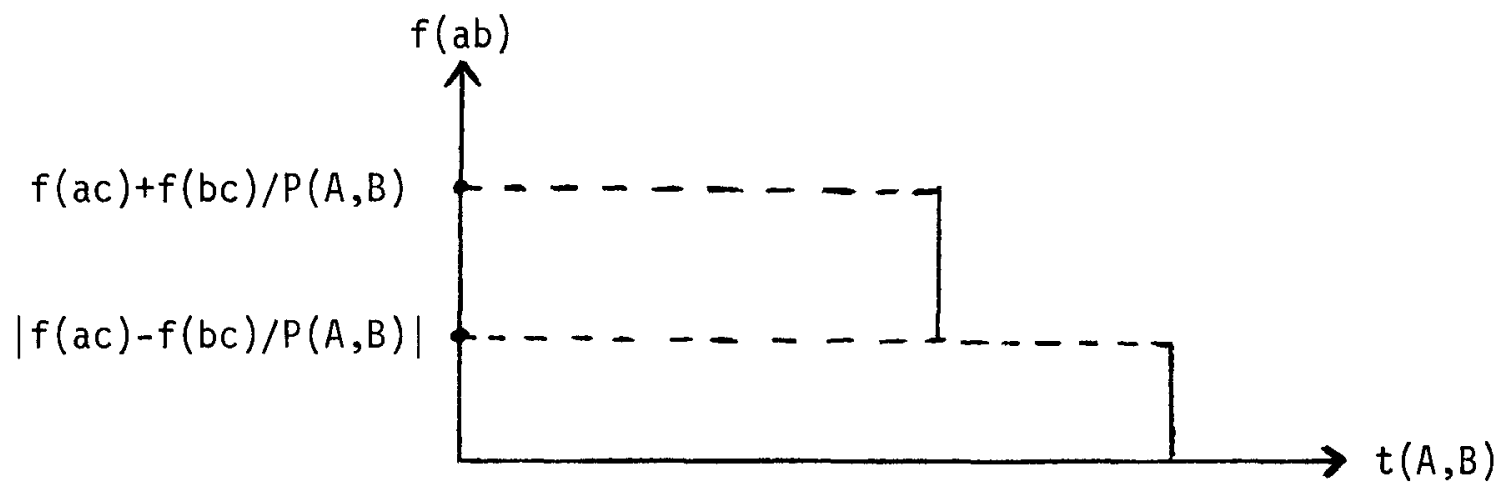

Analogous demand conditions hold for the other two markets.

Several conclusions emerge from the description of demand conditions. First, there are ranges of fees for the three markets that are consistent with non-zero demands in 111 three markets; that is, conditions (1)-(3) can hold simultaneously and, if they do, the equilibrium market structure is the structure consisting of all three markets, the nonmoney structure 1. On the demand side, nothing automatically forces a money structure upon the system. Second, there is a choice of exchange route only under structure 1, but while there is a choice under structure 1 , there - will in general be a preferred route, the direct route. There is complete indifference as to trading route only when (1)-(3) reduce to equalities, but that necessitates zero fees in all markets.

3. The Cost of Providing Transaction or Dealer Services The cost of operating a market depends on the intrinsic properties 
of the commodities traded and on the transaction rate. Since a dealer in a particular market will on average be holding inventories of both the commodities being traded, the properties of those commodities that are important are those that determine the costs of holding inventories; for example, storage and depreciation rates. In what follows below, we will find it useful to refer to a production function for the provision of transaction services. We have already suggested that among the inputs into such a production function are inventories of the commodities being traded. In addition, there will be other inputs; labor, for example. Below, we shall contrast constant and increasing returns to scale production functions. Throughout, we shall assume that inputs are supplied at constant prices to what might be called the transaction service industry.

\section{Equilibrium Exchange Structures}

We shall consider possible equilibrium exchange structures, assuming that demand conditions, the $T$ 's, and net exchange ratios, the $P^{\prime}$ 's, are such that there is zero net average excess demand for each commodity; namely, that

(4) $T(A, B)-T(B, A) P(A, B)+[T(A, C)-T(C, A) P(A, C)]=0$

(5) $T(B, A)-T(A, B) / P(A, B)+[T(B, C)-T(C, B) P(B, C)]=0$

(6) $T(C, A)-T(A, C) / P(A, C)+[T(C, B)-T(B, C) / P(B, C)]=0$

Given those basic equilibrium conditions, we shall consider certain special patterns of T's, all of which satisfy those conditions.

(a) Bilateral balance

We define bilateral balance as $T(I, J)-T(J, I) P(I, J)=0$ for one and, hence, by conditions (4)-(6), all pairs $(\mathrm{I}, \mathrm{J})$. Given bilateral 
balance, it follows that whatever the exchange structure--remember with three commodities there are four possible structures--each dealer shall be in equilibrium in the sense that, on average, his inventories of both commodities shall be constant. Given this demand structure, assume first that average costs are constant for each of the three potential markets-namely, that production functions exhibit constant returns to scale--and that exchange services are priced at average cost. Our assumption of exogenous transaction rates among commodities implies that the optimum exchange structure is the least cost exchange structure. And the constant cost and pricing assumptions imply that the same structure is both the equilibrium and least cost structures.

The problem, though, is that under those conditions, it is hard to see how a money structure could be the equilibrium structure. From conditions (1)-(3), if we choose units so that exchange ratios are unity, as we are free to do, a money structure emerges only if at all output levels average transaction costs in one of the markets is greater than the sum of transaction costs in the other two markets, a stringent condition that could only arise by way of an intrinsic superiority by a wide margin of one of the commodities. Indeed, given that the dealer in any market must, on average, hold inventories of both commodities traded in his - market, the condition could be satisfied only if there are negative costs to holding inventories of one of the commodities. The stringency of that condition--and it is, of course, more stringent if average costs increase-leads one to suspect that decreasing costs form an important element in an explanation of why money exchange structures are a pervasive phenomenon. If we assume that production functions exhibit economies of scale--and 
both implications of inventory theory and certain corroborative evidence support that assumption---then a money exchange can emerge with smaller differences between the intrinsic properties of commodities. Of course, then as has been noted by Niehans and others, - neither average nor marginal cost pricing of exchange services assures that the equilibrium and the optimum exchange structures are the same.- Optimality aside, though, our main conclusion is that under bilateral balance, we can account

I H. Demsetz finds that spreads on the New York Stock Exchange decline as the transaction rate increases. See "The Cost of Transacting," Quarterly Journal of Economics, Vol. 82, No. 1, p. 33.

I See J. Niehans, "Money in a Static Theory of Optimal Payments Arrangements," Journal of Money, Credit, and Banking, Nov. 1969.

/ For example, suppose that all net exchange ratios equal unity, that al1 exogenous transaction rates measured in units of $A$ equal $T$, and that the average cost curves for two markets are identical and denoted by the function $\mathrm{g}$ and that the average cost curve for the third market is $\mathrm{g}+\mathrm{e}$, where $e$ is a positive constant. Then with three markets in existence, each operating at output $2 \mathrm{~T}$, total costs are

$$
C(3)=4 g(T) T+2[g(T)+e] T=2[3 g(T)+e] T .
$$

With the high cost market not operating and with each of the other markets operating, therefore, at output $4 \mathrm{~T}$, total costs are

$$
C(2)=4[g(2 T)] 2 T=8 g(2 T) T .
$$

Thus, $C(3) \geq C(2)$ as $g(T) \geq(4 / 3) g(2 T)-e / 3$. It turns out that neither average nor marginal cost pricing assures the achievement of the optimal result. Under average-cost pricing, equations (1)-(3) imply that three markets are viable if $g(T)+e<2 g(2 T)$. It is clear that this condition and $C(3)>C(2)$ can hold simultaneously. Under marginal cost pricing, (1)-(3) imply that three markets will exist if

$$
g(T)+e<\left[4 g^{\prime}(2 T)-g^{\prime}(T)\right] T+4 g(2 T),
$$

which also can hold if $C(3)>C(2)$; for example, if $g(T)=1 / T^{\frac{1}{2}}$. 
for the pervasiveness of money exchange structures only by way of economies of scale in the provision of transaction services.

(b) Extreme bilateral imbalance

We may characterize extreme bilateral imbalance by $T(B, A)=T(A, C)=T(C, B)=0$. Such imbalance implies--as does any set of demand conditions other than bilateral balance--that if all three markets are operating with non-zero demands for transaction services, then each dealer is not in equilibrium. Indeed, the dealer in $(A, B)$ is on average building inventories of $A$ at the rate $T(A, B)$ and being depleted of inventories of $B$ at the rate $T(A, B) / P(A, B)$, and, analogous $1 y$, for the dealers in the $(A, C)$ and $(B, C)$ markets. In contrast, if any of the money structures prevail, then each dealer is in equilibrium. In fact, the conditions for dealer equilibrium under any of the money structures are identical to conditions (4)-(6). Can we then rule out the nonmoney structure for the case of bilateral imbalance?

If bilateral imbalance and the nonmoney exchange structure are to coexist, some kind of dealer clearing arrangement must be appended to the exchange structure. If we allow the dealers, all three of them, to get together and engage in a multilateral exchange and allow them to do that costlessly, then the distinction between bilateral balance and imbalance is unimportant. But if we do not allow that and, suppose that we do not, then dealer equilibrium can be attained only if dealers themselves place orders on other markets. For example, if one of the dealers simultaneously placed orders on the other two markets such that the execution of those orders would leave him with average unchanged inventories, 
then inclusive of his demands, the other two dealers would find themselves in equilibrium; that is, with unchanged inventories on average. But if the dealer who places those orders bears fees equal to those charged nondealers, then in the case of extreme bilateral imbalance, he must charge a fee to his customers that implies a violation of one of conditions (1)-(3). That is, the fee he charges must be such as to lead his customers to deal indirectly themselves by way of the other two markets. Armed with that conclusion, we may turn to a discussion of the $n$ commodity case.

(c) The case of $n$ commodities

With $n$ commodities, there are $n(n-1) / 2$ possible different two-way markets. The minimum number of markets that allows any commodity to be exchanged for any other, possibly indirectly, is $n-1$. The special feature of al1 such minimum number exchange structures is that the conditions for individual dealer market equilibrium under such structures are identical with the conditions for zero excess demands for all commodities, the $n$ commodity analogues of conditions (4)-(6). For $n$ greater than three, though, all structures consisting of the minimum number of markets are not money exchange structures. In that sense, the three-commodity case was misleading. Before considering alternative exchange structures consisting of the minimum number of markets, I wish to take up a preliminary question. For $n$ large, do we expect demand conditions to approximate bilateral balance or extreme bilateral imbalance?

Consider two examples. Suppose the commodities are $n$ different national currencies. The analogues of conditions (4)-(6) state that each country is in balance of payments equilibrium. Given that condition, is 
it likely that each country is in pairwise balance of payments equilibrium with each other country? For large $n$, clearly not. Next, suppose that the commodities are common stock of different companies. How likely is it that the excess demand for stock of company $A$ on the part of those who wish to sell stock of company $B$ in order to acquire the stock of $A$ matches the excess demand for stock of company $B$ on the part of those who wish to sell stock of $A$ in order to acquire stock of $B$ ? Very unlikely. Indeed, for $n$ large, these examples suggest that demand conditions are likely to approximate extreme bilateral imbalance.

Given that feature of a system with a large number of commodities, it follows that any exchange structure not consisting of the minimum number of markets requires either a multilateral clearing arrangement among dealers, or transactions by certain of the dealers in other markets that imply individual market clearing for all markets. For $n$ large, there is a good case for ruling out multilateral clearing, and, for near extreme bilateral imbalance, dealers forced to place orders on other markets and to bear fees cannot charge fees that draw customers. That establishes a prima facie case that in a system with a large number of commodities, the equilibrium exchange structure is one that consists of the minimum number of markets. That leaves us with having to explain why, among structures with the minimum number of - markets, money exchange structures seem to be dominant.

To clarify the question, Figure 2 for the case of four commodities shows the two kinds of exchange structures that consist of the minimum number of markets, which is three for the case of four commodities. 
Figure 2. Kinds of Minimum-Number Market Structures with Four Commodities

(a)

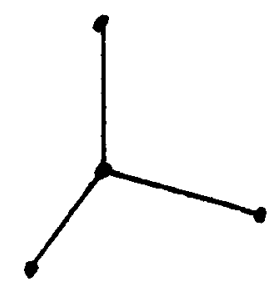

(b)

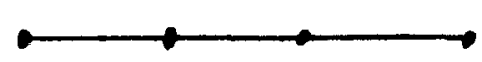

In the figure, points represent commodities, and line segments joining them the presence of a market in which the two commodities are exchanged, one for the other. Part (a) shows a money exchange structure. There are four different possible money structures, each having as the commodity money a different commodity. Part (b) shows the only kind of nonmoney structure consisting of the minimum number of markets. There are 12 different such structures, each corresponding to a different labelling by commodity of the points in the figure. The money structures are characterized by an obvious economy. The maximum number of exchanges required is two. Indeed, we in effect defined a money structure that way. For the kind of structure illustrated in part (b), there are some exchanges that require dealings in three markets. That result generalizes, and establishes the case that among structures consisting of the minimum number of markets, money structures are on average least cost.

\section{Conclusion}

The questions that often arise about money and nonmoney economies are what are the gains and losses from a movement from a nonmoney economy to a money economy, or vice versa; or what are the gains and losses from replacing one kind of money by another. In our framework, exogenous changes in the depreciation rate of one of the commodities could lead to such changes. 
Alterations in the expected rate of inflation are an example of changes in the depreciation rate of a money. Unfortunately, we can say very little about the gains and losses that accompany such changes. The framework above allows an analysis only of the effects on resources employed in the transaction service industry at given transaction rates, the T's. - But, among all effects, those may be relatively minor. To analyze the effects of a change in transaction costs holding the T's constant is analogous in the transport problem to analyzing the effects of a change in transport costs holding the ultimate destination network of trips constant and allowing only rerouting of trips. But, surely, among the important effects of a change in transport costs are changes in the ultimate destination network of trips. In the case of a decline in transport costs, some goods that previously did not enter trade do, and so on. A complete analysis of alternative exchange structures should, therefore, include an analysis of desired transaction rates among commodities. But that involves questions that economists are only beginning to take up. That may be seen from the following examples, which illustrate some of the directions in which we are led by considering a dependence of the T's on the cost of transacting. (i) A usefur interpretation of the notion of "fixed" factors of production is that firms face large bid-ask spreads in the markets for those factors. Such spreads produce . long holding periods, which, for given stocks are synonomous with low transaction rates. (ii) A special case of the above applies to security markets. Transaction costs can make it unprofitable to undertake transactions to wipe

I Friedman judges economies with different kinds of money partly by that criterion. See "Commodity Reserve Currency," in Essays in Positive Economics, University of Chicago Press (1953). 
out all differences in own expected rates of return. Without taking account of that, Fama, Shelton, and Theil and Leenders claim to have found evidence that contradicts the random-walk hypothesis, or, more generally, the hypothes is that market prices of assets at any point in time are determined so that expected rates of return are equalized. I To the extent that transaction costs in different markets can account for the observed departures from randomness, those findings constitute evidence consistent with a dependence of desired transaction rates on the cost of transacting. (iii) If the commodities are different national currencies, a dependence of desired transaction rates on the cost of transacting means a dependence of the volume of international trade and asset exchanges on the costs of exchanging currencies.

In defense of the framework set out above, it does suggest new ways to examine phenomena that have attracted much attention but from a different point of reference. One example is markets among national currencies: the nature of the structure, and how and why it has changed over time. Another is the structure of markets in some developing countries where, it is often claimed, a "nonmonetary" sector coexists with a monetary sector. The approach taken also emphasizes the fact that questions concerning the role of money in an economy are part of a broader class of questions concerned with the organization of markets in general and with the activity of trading or exchanging - as a resource using activity. The framework developed allows us to define money and nonmoney economies and to begin the task of comparing them.

I H. Theil and C. T. Leenders, "Tommorrow on the Amsterdam Stock Exchange;" E. F. Fama, "Tommorrow on the New York Stock Exchange," (Journal of Business, Vol. 38, pp. 277-299); and J. P. Shelton, "The Value Line Contest: A Test of the Predictability of Stock-Price Changes," (Journal of Business, Vol. 40, pp. 251-269) all find departures from the randomwalk hypothesis. In Shelton's case, for which it is easy to make the computation, transaction costs on the New York Stock Exchange are more than sufficient to explain the degree of departure from randomness that he finds. 